\title{
Design and preliminary validation of a tool for the simulation of train braking performance
}

\author{
Luca Pugi • Monica Malvezzi · Susanna Papini • \\ Gregorio Vettori
}

Received: 18 March 2013/Revised: 24 June 2013/Accepted: 13 September 2013/Published online: 19 December 2013

(C) The Author(s) 2013. This article is published with open access at Springerlink.com

\begin{abstract}
Train braking performance is important for the safety and reliability of railway systems. The availability of a tool that allows evaluating such performance on the basis of the main train features can be useful for train system designers to choose proper dimensions for and optimize train's subsystems. This paper presents a modular tool for the prediction of train braking performance, with a particular attention to the accurate prediction of stopping distances. The tool takes into account different loading and operating conditions, in order to verify the safety requirements prescribed by European technical specifications for interoperability of high-speed trains and the corresponding EN regulations. The numerical results given by the tool were verified and validated by comparison with experimental data, considering as benchmark case an Ansaldo EMU V250 train—a European high-speed train—currently developed for Belgium and Netherlands high-speed lines, on which technical information and experimental data directly recorded during the preliminary tests were available. An accurate identification of the influence of the braking pad friction factor on braking performances allowed obtaining reliable results.
\end{abstract}

Keywords Braking performances - Friction behavior of braking pads $\cdot$ Prediction tool

L. Pugi $(\bowtie) \cdot$ S. Papini · G. Vettori

Department of Industrial Engineering, University of Florence,

Via Santa Marta 3, 50139 Florence, Italy

e-mail: luca.pugi@unifi.it

M. Malvezzi

Department of Information Engineering and Mathematical Science, University of Siena, Via Roma 26, 53100 Siena, Italy

\section{Introduction}

Braking performance is a safety relevant issue in railway practice, impacting vehicle longitudinal dynamics, signaling, and traffic management, and its features and requirements are important also for interoperability issues [1].

EN 14531 regulation [2] provides indications concerning preliminary calculation of braking performance, giving a general workflow that can be adapted to different vehicle categories:

- Freight wagons,

- Mass transit,

- Passenger coaches,

- Locomotives, and

- High-speed trains.

The aim of the regulation [2] is to set a general method that should be shared among different industrial partners (industries, railway operators, safety assessors, etc.).

The availability of software tools aimed to simulate the performance of braking system is useful to speed up and optimize the design process [3]. Braking performance evaluation is also necessary to properly quantify the intervention curve of automatic train protection (ATP) systems [4, 5]. Some examples of train brake system simulators are available in the literature. In [6], David et al. presented a software tool for the evaluation of train stopping distance, developed in C language. In [7], the software TrainDy was presented; it was developed to reliably evaluate the longitudinal force distribution along a train during different operations. In [8], Kang described a hardware-in-the-loop (HIL) system for the braking system of the Korean high-speed train and analyzed the characteristics of the braking system via real-time simulations. In [9], many interrelationships between various factors and types of braking techniques were analyzed. 
A simple but reliable tool able to simulate and predict the performances of braking system on the basis of a limited and often uncertain set of parameters could be useful and give interesting information to the designers on how to choose and optimize brake features, especially in the first phase of the design process of a new train.

In this work, the authors have developed a Matlab ${ }^{\mathrm{TM}}$ tool called "TTBS01", which implements the method for the calculation of braking performances described in [2]. The tool has been validated on experimental results concerning AnsaldoBreda EMU V250. The results, which will be detailed through this paper, showed an acceptable agreement with experimental tests, and then confirmed the reliability of the proposed tool and its applicability to the prediction of stopping distance of different types of trains in various operative conditions, including degraded conditions and failure of some subsystems. The proposed tool can thus be adopted in the design phase to choose proper dimensions of the braking system components and to preliminarily evaluate their performance.

Since the detailed description of the calculation method is directly available on the reference regulation [2], in this work, the authors will give a more general description of the

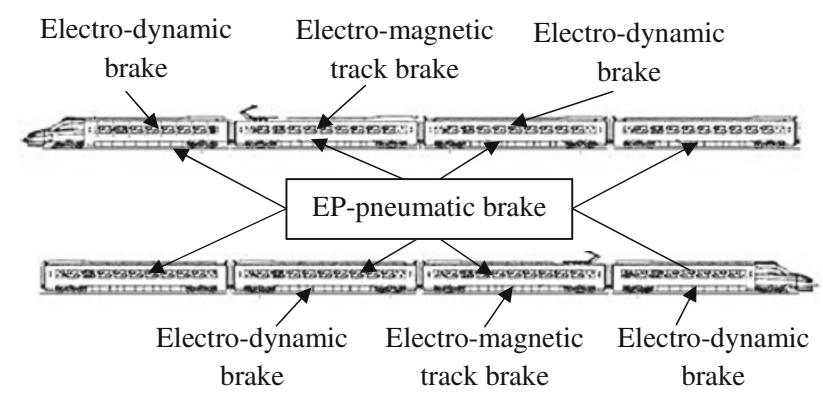

Fig. 1 EMU V250 vehicle composition and braking plant layout algorithm, focusing mainly on the considered test case, the numerical results, and the matters that have proven to be critical during the validation activities. A particular attention has been paid to some features that are originally not prescribed by the regulations in force, but could be considered to further increase result accuracy and reliability. In particular, some parameters, such as friction factor of braking pads, which should be slightly variable according to different operating conditions, were identified and tabulated.

\section{The test case: the EMU V250 train}

The simulation tool described in this paper, named "TTBS01", was tested and validated using the data obtained on an Ansaldo EMU V250 train: a high-speed electrical multiple unit for passenger transport with a maximum operating speed of $250 \mathrm{~km} / \mathrm{h}$ (maximum test speed $275 \mathrm{~km} / \mathrm{h}$ ), composed of two train sets of eight coaches. The traction is distributed with alternating motor and trailer vehicles in the sequence "MTMTTMTM", where $M$ indicates motorized coaches and $T$ the trailer ones. The arrangement of each motorized wheelset is B0B0. Train composition is shown in Fig. 1: the motorized coach traction motors can be used for electro-dynamic braking types, both regenerative and dissipative. The 2 nd and the 7 th coaches are equipped with an electro-magnetic track brake that should be adopted in emergency condition. The mandatory pneumatic braking system is implemented with the support of both direct and indirect electro-pneumatic (IEP) operating modes: the braking command can be directly transmitted by wire to the BCU (braking control unit) on each coach, or indirectly, by controlling the pressure of the pneumatic pipe, as seen in the simplified scheme shown in Fig. 2.

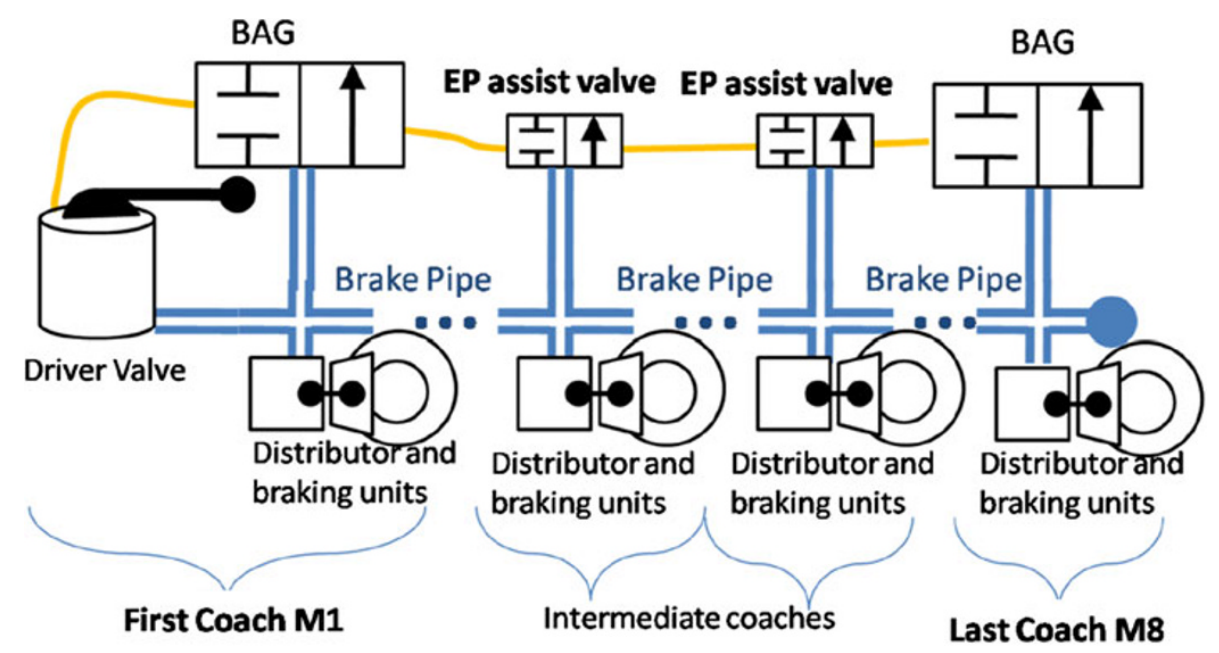

Fig. 2 Braking plant in the IEP mode 


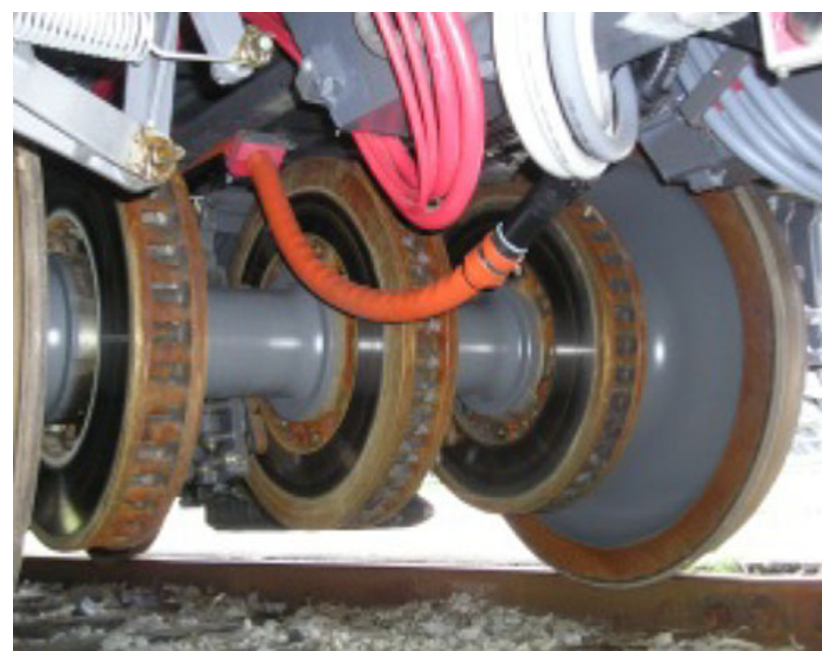

Fig. 3 Brake disks on trailer bogie

Finally, a backup mode where the brake plant is controlled as a standard pneumatic brake ensures interoperability with vehicles equipped with a standard UIC brake. Each axle is equipped with three brake disks for trailing axles (as in Fig. 3), and two for the motorized ones, where electric braking is available, too. In this configuration, the magnetic track brake should be available, since a pressure switch commanded using the brake pipe controls the track lowering (threshold at 3 bar absolute).

The corresponding configuration of the pneumatic brake plant and the inertia values used for calculations are described in Tables 1 and 2.
2.1 Further controls: double pressure stage and load sensing

The pressure applied to brake cylinders and consequently the clamping and braking forces are regulated as a function of train mass (load sensing) and speed (double pressure stage). Load sensing allows optimizing braking performance with respect to vehicle inertia and weight. Double pressure stage allows protecting friction components against excessive thermal loads (double pressure stage). Both the systems allow preventing over-braking: according to the regulations [1] and [10], braking forces applied to wheels have to be limited, in order to prevent over-braking, defined as "brake application exceeding the available wheel/rail adhesion".

In particular, the braking forces are usually regulated, e.g. on freight trains, using a load-sensing pressure relay, simplified scheme of which is represented in Fig. 4. A sensing device mounted on the primary suspension stage produces a pressure load signal that is approximately proportional to the axle load. The reference pilot pressure command, produced by the brake distributor, is amplified by the relay in order to feed brake cylinders, using the leverage schematically represented in Fig. 4. The systems work as a servo pneumatic amplifier with a pneumomechanic closed-loop regulation, aiming to adapt the pneumatic impedance of the distributor output to the flow requirements of the controlled plant. The gain is adjustable since the pivot of the leverage, and consequently, the amplification ratio is regulated by the pressure load signal.

Table 1 Main parameters of the braking plant $[5,6]$

\begin{tabular}{|c|c|c|c|c|c|c|c|c|c|c|}
\hline Coach & Bogie & $\begin{array}{l}\text { Wheel } \\
\text { diameter } \\
(\text { new })(\mathrm{mm})\end{array}$ & $\begin{array}{l}\text { Wheel } \\
\text { diameter } \\
\text { (worn) (mm) }\end{array}$ & $\begin{array}{l}\text { Brake } \\
\text { radius } \\
(\mathrm{mm})\end{array}$ & $\begin{array}{l}\text { Number } \\
\text { of disks/ } \\
\text { axle }\end{array}$ & $\begin{array}{l}\text { Dynamic } \\
\text { pad friction } \\
\text { level }\end{array}$ & $\begin{array}{l}\text { Brake actuator } \\
\text { piston surface } \\
\left(\mathrm{cm}^{2}\right)\end{array}$ & $\begin{array}{l}\text { Spring counter } \\
\text { force/actuator } \\
\text { (N) }\end{array}$ & $\begin{array}{l}\text { Caliper } \\
\text { efficiency }\end{array}$ & $\begin{array}{l}\text { Ratio of } \\
\text { the } \\
\text { caliper }\end{array}$ \\
\hline \multirow[t]{2}{*}{ M1 } & 1 & 920 & 850 & 299 & 2 & 0.42 & 506,7 & 1,300 & 0.95 & 2.82 \\
\hline & 2 & 920 & 850 & 299 & 2 & 0.42 & 506,7 & 1,300 & 0.95 & 2.82 \\
\hline \multirow[t]{2}{*}{$\mathrm{T} 2$} & 3 & 920 & 850 & 243 & 3 & 0.42 & 506,7 & 1,300 & 0.95 & 2.69 \\
\hline & 4 & 920 & 850 & 243 & 3 & 0.42 & 506,7 & 1,300 & 0.95 & 2.69 \\
\hline \multirow[t]{2}{*}{ M3 } & 5 & 920 & 850 & 299 & 2 & 0.42 & 506,7 & 1,300 & 0.95 & 2.82 \\
\hline & 6 & 920 & 850 & 299 & 2 & 0.42 & 506,7 & 1,300 & 0.95 & 2.82 \\
\hline \multirow[t]{2}{*}{$\mathrm{T} 4$} & 7 & 920 & 850 & 243 & 3 & 0.42 & 506,7 & 1,300 & 0.95 & 2.69 \\
\hline & 8 & 920 & 850 & 243 & 3 & 0.42 & 506,7 & 1,300 & 0.95 & 2.69 \\
\hline \multirow[t]{2}{*}{ T5 } & 9 & 920 & 850 & 243 & 3 & 0.42 & 506,7 & 1,300 & 0.95 & 2.69 \\
\hline & 10 & 920 & 850 & 243 & 3 & 0.42 & 506,7 & 1,300 & 0.95 & 2.69 \\
\hline \multirow[t]{2}{*}{ M6 } & 11 & 920 & 850 & 299 & 2 & 0.42 & 506,7 & 1,300 & 0.95 & 2.82 \\
\hline & 12 & 920 & 850 & 299 & 2 & 0.42 & 506,7 & 1,300 & 0.95 & 2.82 \\
\hline \multirow[t]{2}{*}{$\mathrm{T} 7$} & 13 & 920 & 850 & 243 & 3 & 0.42 & 506,7 & 1,300 & 0.95 & 2.69 \\
\hline & 14 & 920 & 850 & 243 & 3 & 0.42 & 506,7 & 1,300 & 0.95 & 2.69 \\
\hline \multirow[t]{2}{*}{ M8 } & 15 & 920 & 850 & 299 & 2 & 0.42 & 506,7 & 1,300 & 0.95 & 2.82 \\
\hline & 16 & 920 & 850 & 299 & 2 & 0.42 & 506,7 & 1,300 & 0.95 & 2.82 \\
\hline
\end{tabular}


Table 2 Vehicle loading conditions and inertia values for braking plant calculation $[5,6]$

\begin{tabular}{|c|c|c|c|c|c|c|c|}
\hline Coach & Bogie & VOM load (Tare) (t) & TSI load (t) & $\mathrm{CN}$ load (normal) (t) & CE load (exceptional) (t) & Bogie mass $(\mathrm{t})$ & Rotating mass/axle ( $\mathrm{t}$ ) \\
\hline \multirow[t]{2}{*}{ M1 } & 1 & 15.9 & 16.7 & 17 & 17.6 & 9.93 & 1.5 \\
\hline & 2 & 13.9 & 15 & 15.4 & 16.3 & 9.81 & 1.5 \\
\hline \multirow[t]{2}{*}{$\mathrm{T} 2$} & 3 & 13.9 & 15 & 15.3 & 16.6 & 7.85 & 0.6 \\
\hline & 4 & 14 & 15.1 & 15.4 & 16.5 & 7.85 & 0.6 \\
\hline \multirow[t]{2}{*}{ M3 } & 5 & 13.6 & 14,8 & 15.2 & 16.1 & 9.81 & 1.5 \\
\hline & 6 & 14.1 & 15.5 & 15.9 & 16.8 & 9.81 & 1.5 \\
\hline \multirow[t]{2}{*}{ T4 } & 7 & 11.2 & 12.8 & 13.3 & 14.2 & 7.85 & 0.6 \\
\hline & 8 & 12.1 & 13.7 & 14.2 & 15 & 7.85 & 0.6 \\
\hline \multirow[t]{2}{*}{ T5 } & 9 & 12 & 13.6 & 14.1 & 14.9 & 7.85 & 0.6 \\
\hline & 10 & 11.3 & 12.8 & 13.2 & 14.1 & 7.85 & 0.6 \\
\hline \multirow[t]{2}{*}{ M6 } & 11 & 14.1 & 15.7 & 16.2 & 17 & 9.81 & 1.5 \\
\hline & 12 & 13.8 & 15.3 & 15.8 & 16.7 & 9.81 & 1.5 \\
\hline \multirow[t]{2}{*}{ T7 } & 13 & 14 & 15.6 & 16.1 & 16.9 & 7.85 & 0.6 \\
\hline & 14 & 14.1 & 15.6 & 16.1 & 17 & 7.85 & 0.6 \\
\hline \multirow[t]{2}{*}{ M8 } & 15 & 13.7 & 15.2 & 15.7 & 16.5 & 9.81 & 1.5 \\
\hline & 16 & 15.9 & 16.9 & 17.2 & 17.8 & 9.93 & 1.5 \\
\hline \multicolumn{2}{|c|}{ Train mass (t) } & 435.2 & 478.6 & 492.2 & 520 & & \\
\hline \multicolumn{2}{|c|}{$\begin{array}{l}\text { Train rotating } \\
\text { mass }(\mathrm{t})\end{array}$} & & & & & & 33.6 \\
\hline
\end{tabular}

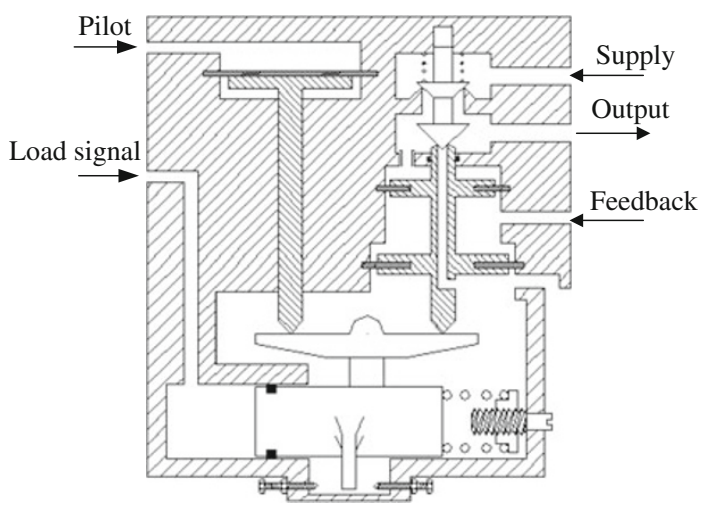

Fig. 4 Pressure relay/load-sensing device

On freight trains, where the difference between the tare and fully loaded vehicle masses could be in the order of $300 \%$ (from 20 to $30 \mathrm{t} / \mathrm{vehicle}$ for the empty wagon to $90 \mathrm{t} / \mathrm{vehicle}$ for the fully loaded one), load sensing is very important. For high-speed trains, such as EMU V250, the difference between VOM and CE loading conditions, as visible in Table 2, is not in general lower than $10 \%-20 \%$.

As a consequence, the corresponding variation in terms of deceleration and dissipated power on disks is often numerically not much relevant and is partially tolerated by regulations in force [10] for high-speed trains with more than 20 axles, in emergency braking condition or in other backup mode, where the full functionality of the plant should not be completely available.
For the reasons of safety, the correct implementation of the double stage pressure ensuring that lower pressure is applied on cylinders for traveling speed of over $170 \mathrm{~km} / \mathrm{h}$ is much more important. This is important because the energy dissipated during a stop braking increases approximately with the square of train traveling speed and, as a consequence, a reduction of disk clamping forces may be fundamental to avoid the risk of excessive thermal loads. Furthermore, the adhesion limits imposed by [10] prescribe a linear reduction of the braking forces between 200 and $350 \mathrm{~km} / \mathrm{h}$, according to a linear law which corresponds to a reduction of the braking power of about one-third in the above-cited speed range.

\subsection{Electrical braking and blending}

Electrical or electro-dynamical brakes are a mandatory trend for a modern high-speed train. Most of the more modern EMUs have the traction power distributed over a high number of axles. On EMU V250 train, nearly $50 \%$ of the axles is motorized and nearly $55 \%$ of the total train weight is supported by motorized bogies.

As a consequence, a considerable amount of the total brake effort should be distributed to traction motors, by performing regenerative or dissipative braking, according to the capability of the overhead line for managing the corresponding recovered power. In particular, not only regenerative but also dissipative electric braking is quite attractive, considering the corresponding reduction of wear 
of friction braking components such as pads and disks. Since electric braking is applied in parallel with the conventional pneumatic one, an optimized mixing strategy in the usage of both systems, usually called blending, has to be performed.

In Fig. 5, the electric braking effort available on a motorized coach as a function of the train traveling speed and of the electrification standard of the overhead line is shown. Three different operating conditions can be recognized:

- Maximum pneumatic braking force: under a certain traveling speed, the corresponding operating frequencies of the traction system are too low. On the other hand, also the demanded braking power is quite low, and so it can be completely managed by means of the pneumatic braking system.

- Minimum pneumatic braking: in this region, the electric braking effort is limited to a maximum value, often related to the motor currents. If a higher braking effort is required, then the pneumatic brake is activated to supply the difference.

- Pneumatic braking increases to supply insufficient electric power: as speed increases, the performances of the motor drive system are insufficient to manage the corresponding power requirements, limiting the maximum braking effort to the associated iso-power curve. As a consequence, the contribution of the pneumatic braking power tends to increase with speed.

\section{Summary of the European standards for brake calculation}

The EN 14531 (first draft 2003) describes the fundamental algorithms and calculations for the design of brake equipment for railway vehicles. The procedure provides the calculation of various aspects related to the performance: stopping or slowing distances, dissipated energy, force calculations, and immobilization braking. For the purposes of this work, the Part 6 of the regulation: "Application to high-speed trains" is of interest. The general algorithm to calculate braking distances is described in the regulation: the input data consist of train and brake characteristics, and the method to estimate the deceleration as a combination of different braking forces acting on the train is suggested as a function of the initial speed [1]. Moreover, the criteria for the technical and operational compatibility between the infrastructures and the rolling stock are defined in L.245/ 402 technical specification for interoperability (TSI) published in the Official Journal of the European Communities in 2002. The essential requirements for trans-European high-speed rail systems are related to safety, reliability, availability, health, environmental protection, and technical compatibility. Notably, the brake system requirements for high-speed rail systems are established; i.e., the minimum braking performance is defined as the minimum deceleration and evaluated as a function of speed [2]. On the other hand, the European norm UIC544-1 (4th edition, October 2004) defines the method for computation of the braking power through the braked mass and determination of the deceleration [3].

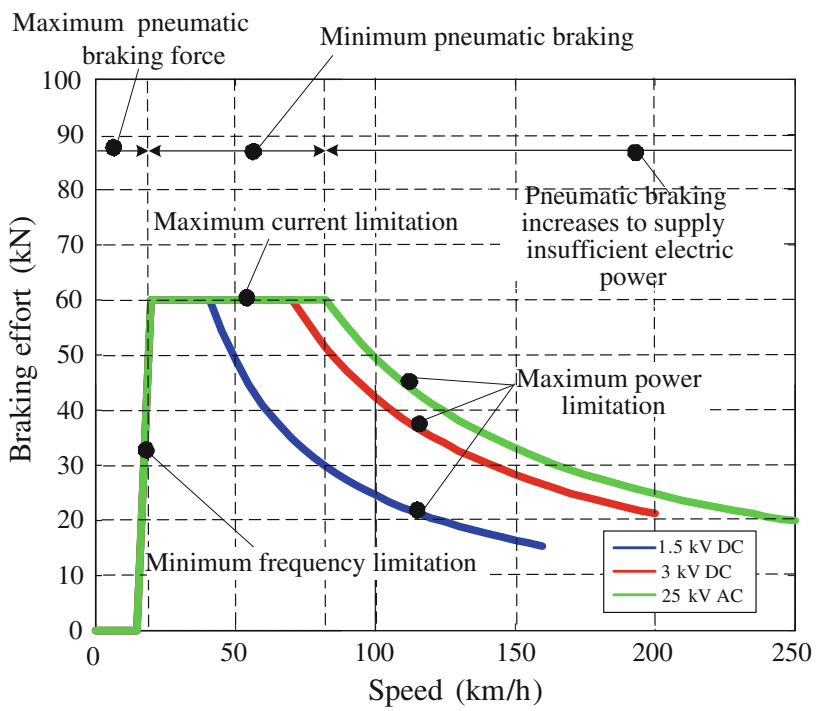

Fig. 5 Typical behaviors of electric and pneumatic braking efforts on motorized bogies

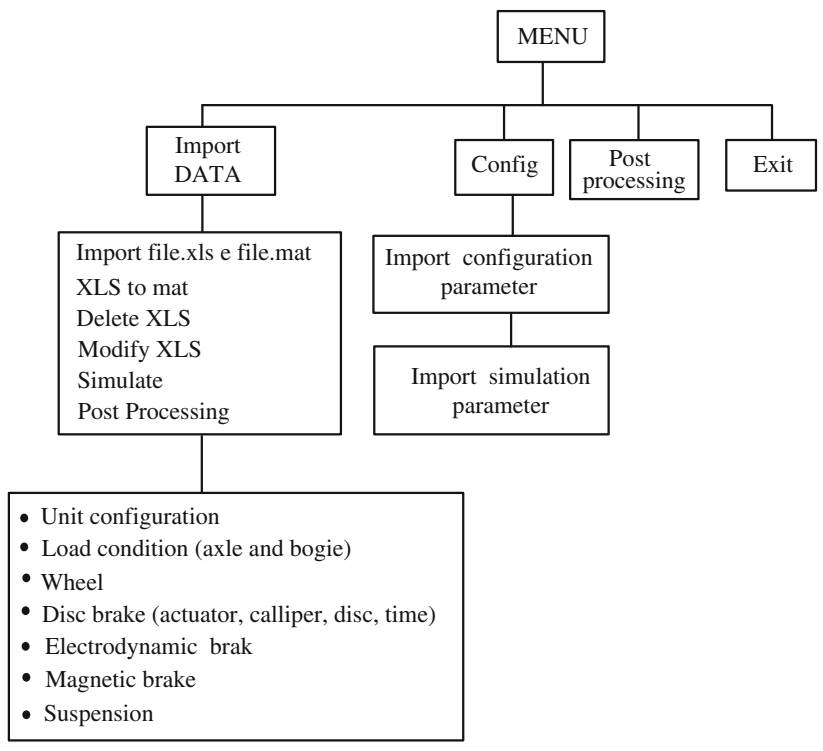

Fig. 6 Interface structure of the TTBS01 tool 


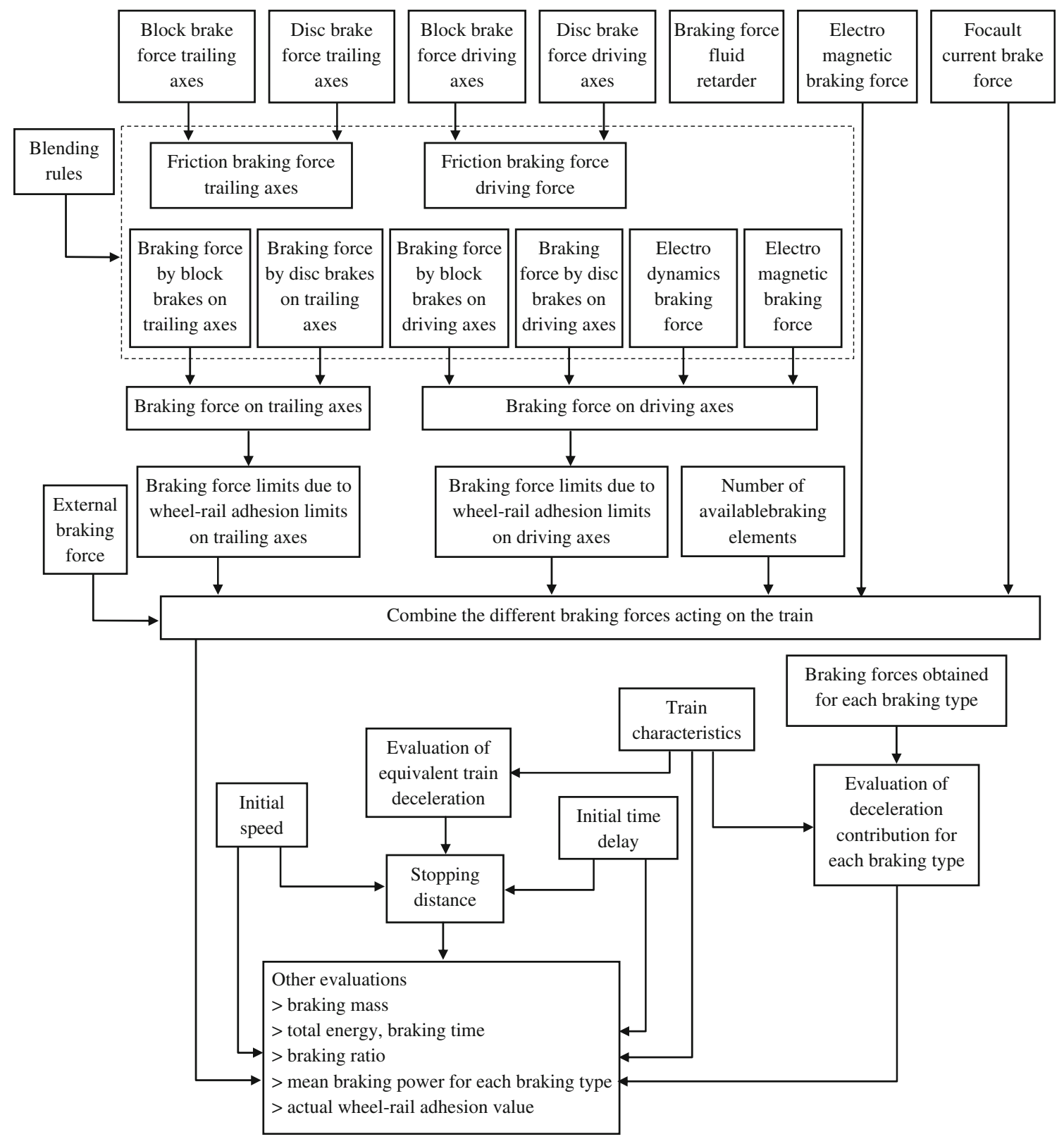

Fig. 7 Flow chart of braking calculations performed according to [2]

\section{Software-TTBS01}

The software tool for the computation of train braking systems, named TTBS01, has been implemented in Mat$\mathrm{lab}^{\mathrm{TM}}$. The algorithm provides a graphical user interface (GUI) to help the user to insert and modify input data. It is organized in different windows and grouped in four sections, as shown in the scheme of Fig. 6 and the software user interface in Fig. 8.

- Pre-processing (Import DATA): the train and simulation data are input by user.

- Configuration (Config.): data are saved and stored in files.
- Calculation: braking system calculation is performed according to [2], and the corresponding flowchart is shown in Fig. 7.

- Post-processing: the user can view the representative brake output in several charts.

\section{Tool validation}

The validation of tool results was carried out by comparing simulation results with test data $[11,12]$. 


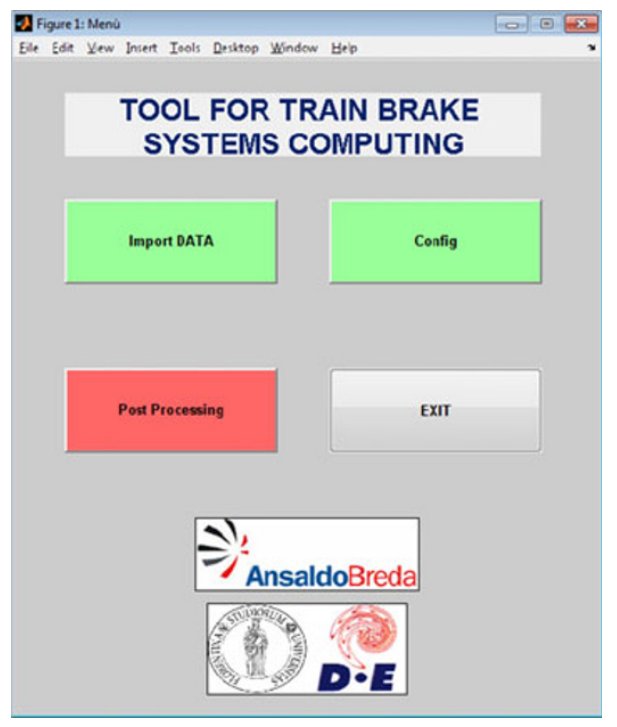

Fig. 8 Main menu window of TTBS01

Totally, a population of about 50 braking test runs was investigated, which were performed on a train equipped with the sensor layout described in Table 3.

The brake performance test concerns the emergency and service braking at several initial speeds, considering the different working and operating conditions of the braking system (direct electro-pneumatic, indirect electro-pneumatic, pneumatic, etc.). The test runs were finished in normal adhesion condition, where the wheel slide protection (WSP) system did not work. The test runs were performed on a complete V250 unit, coaches of which had passed all the single-coach tests, with a fully working braking system (all other subsystems involved in the braking functionality).

The braking runs for the test procedure were performed in three different load conditions: VOM, TSI, and CE, as defined in [1]:

- VOM load condition, defined as mass empty, ready for departure;

- TSI load condition, corresponding to mass normal load; and

- CE load condition, defined as mass exceptional load.

\subsection{Acceptance criteria}

In order to verify and validate the TTBS01 simulation tool, the relative error $e_{\mathrm{S}}$ between the simulated stopping distance $s_{\text {simul }}$ and the experimental one $s_{\text {test }}$ is defined as (1), and the corresponding speed and acceleration profiles have been evaluated.

$e_{\mathrm{s}}=\frac{s_{\mathrm{test}}-s_{\mathrm{simul}}}{s_{\mathrm{simul}}}$

According to [13-16], the repeatability of braking performances in terms of mean deceleration has to satisfy the requirements summarized in Table 4, where the probability of degraded braking performances is shown. The relative error on stopping-braking distance $s$, for an assigned initial speed $v_{0}$, is approximately proportional to the mean deceleration, as stated by (2):

$s=\frac{v_{0}^{2}}{2 a} \Rightarrow \frac{\partial s}{\partial a}=\frac{v_{0}^{2}}{2 a} \Rightarrow \frac{\partial s}{s}=-\frac{\partial a}{a}$.

Table 3 Sensor layout adopted for experimental test runs on EMU V250 [5, 6]

\begin{tabular}{lllll}
\hline & Pressure transducer & Radar Doppler sensor & Servo-acelerometer & Thermocouples \\
\hline Accuracy & $0.5 \%$ respect to full range & $\pm 1 \mathrm{~km} / \mathrm{h}$ & $0.1 \%$ respect to full range & $\mathrm{K}$ type \\
Range & $0-12 \mathrm{bar}$ & $0-500 \mathrm{~km} / \mathrm{h}$ & $1 \mathrm{~g}$ & thermocouples \\
Quantity and layout & 8 pressure transducer on brake plant & $1 / \mathrm{on} \mathrm{a} \mathrm{coach} \mathrm{carbody}$ & $1 / \mathrm{on}$ a coach carbody & $4 /$ on disks \\
\hline
\end{tabular}

Table 4 Statistic distribution of degraded braking performances according to [7, 8]

\begin{tabular}{llllll}
\hline Probability (no. of tests) & $10^{-1}\left(10^{1}\right)$ & $10^{-2}\left(10^{2}\right)$ & $10^{-3}\left(10^{3}\right)$ & $10^{-4}\left(10^{4}\right)$ & $10^{-5}\left(10^{5}\right)$ \\
\hline Mean deceleration & 0.969 & 0.945 & 0.926 & 0.905 & 0.849 \\
Nominal deceleration & $(-3.1 \%)$ & $(-5.5 \%)$ & $(-7.4 \%)$ & $(-9.5 \%)$ & $(-15.1 \%)$ \\
\hline
\end{tabular}

Table 5 Calculated longitudinal eigenfrequencies of EMU V250 according to [17] (Hz)

\begin{tabular}{llllll}
\hline Compostion & First eigenfrequency & Second eigenfrequency & Third eigenfrequency & Fourth eigenfrequency & Fifth eigenfrequency \\
\hline Standard (8 coaches) & 2.4 & 4.7 & 6.9 & 6.9 & 8.8 \\
Doubled (16 coaches) & 1.2 & 2.4 & 3.6 & 4.8 & 5.9 \\
\hline
\end{tabular}


Considering a population of 50 test runs, a $4 \%$ error between simulation and test results was considered as acceptable.

The statistical distribution of the degraded braking performances defined according to $[13,14]$ is summarized in Table 4, which is referred to as a homogenous population of braking tests. Since in the campaign on EMU V250, each test was performed with different boundary and operating variables, a higher variability with respect to the expected simulation results should be expected.

In addition, some further considerations have to be made concerning longitudinal train oscillations. During the tests, a 1-2-Hz longitudinal mode was observed by both speed and acceleration sensors, which accorded with the results of a previous modal analysis [17] as shown in Table 5, and more generally with the typical longitudinal eigenfrequencies of train formations [18, 19]. In particular, the phenomenon is clearly recognizable from the acceleration profiles depicted in Fig. 9, while a qualitative comparison between experimental and simulation speed profiles, with respect to the linear regression curve built on experimental data, is shown in Fig. 10.

This phenomenon causes a variability of about $1-2 \mathrm{~km} / \mathrm{h}$ on the measured speed with respect to the mean value (about 1\%-1.5\% with respect to the launching speed). The sensitivity of error on braking distance to the correct evaluation of the launching speed, as shown in (3),
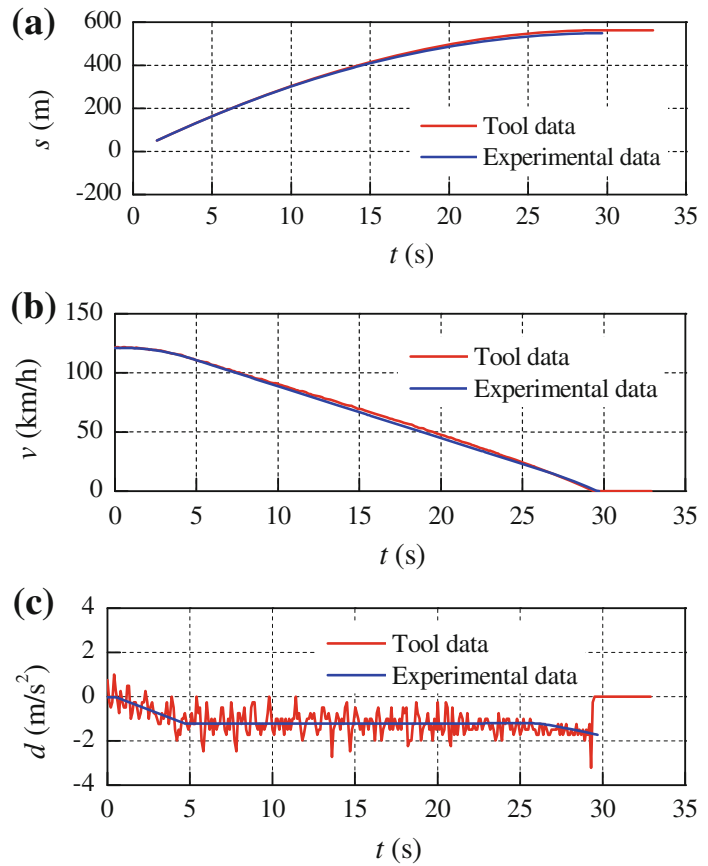

Fig. 9 Space (a), speed (b), and deceleration (c) profiles measured and calculated during a braking maneuver produces about 2-3\% additional uncertainty on estimated braking distance.

$s=\frac{v_{0}^{2}}{2 a} \Rightarrow \frac{\partial s}{\partial v_{0}}=\frac{v_{0}}{a} \Rightarrow \frac{\partial s}{s}=\frac{2 \partial v_{0}}{v_{0}}$.

As a consequence, the authors finally adopted a level of acceptability for the results equal to about 5\%-6\%.

This level of acceptability of test is also indirectly prescribed by UIC544-1 [20], which considers valid the result of braking test if the ratio $\sigma_{\mathrm{r}}$, defined as in (4), is lower than 0.03 for a population of four consecutive test runs.

$\sigma_{\mathrm{r}}=\frac{\sigma}{s_{\text {mean }}}$,

where $s_{\text {mean }}$ is the mean of the measured braking distances, and $\sigma$ is the standard deviation of the difference between the measured and the mean value of the braking distance.

Considering the definition of mean error and standard deviation, the condition (4) corresponds to an admissible relative error on the measured braking distances of about $6 \%-6.5 \%$, which is thus larger than the one adopted for the TTBS01 validation procedure.
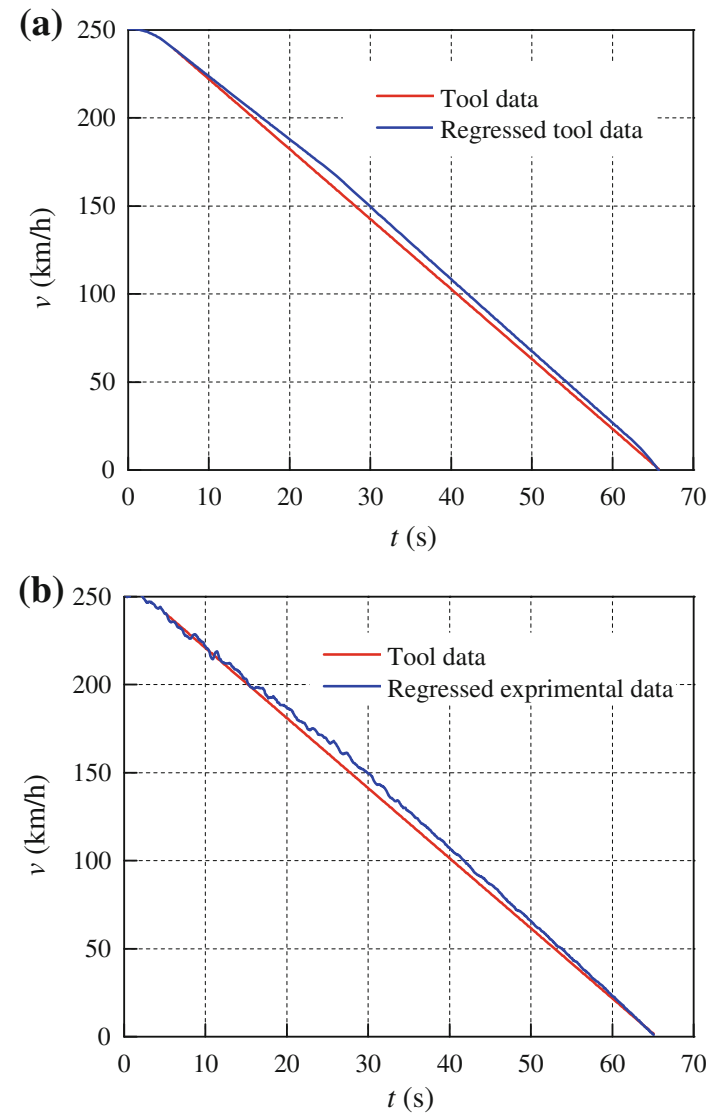

Fig. 10 Comparison between simulated (a) and experimental (b) speed profiles with linear regressed curves 
5.2 Identification of brake pad friction factor and preliminary validation of the tool

Applying the TTBS01 procedure with the calculation described in [2] to the cases covered by the experimental data led to unsatisfactory results in terms of statistical distribution of the error $e_{\mathrm{s}}$, as shown in Fig. 11: only $60 \%$ of the simulated test runs were able to satisfy the requirements, even when considering a $5.5 \%$ admissible value for $e_{\mathrm{s}}$.

Taking the real behavior of a friction brake pad as the example of Fig. 12 [12, 14], the following considerations arise: the brake pad friction factor is clearly dependent on three parameters: the speed, the dissipated energy that mainly depends on clamping forces and starting speed, and the clamping forces applied to the pad. As a consequence,

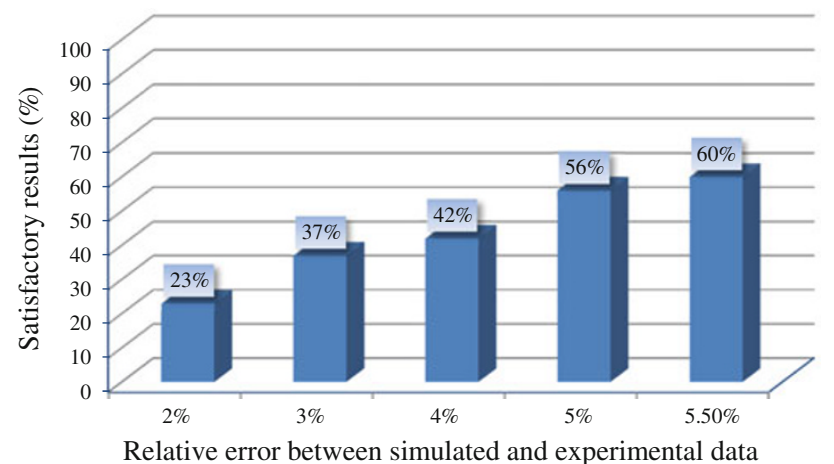

Fig. 11 Number of satisfactory simulated results as a function of the admissible value of $e_{\mathrm{s}}$ (constant brake pad friction faction)

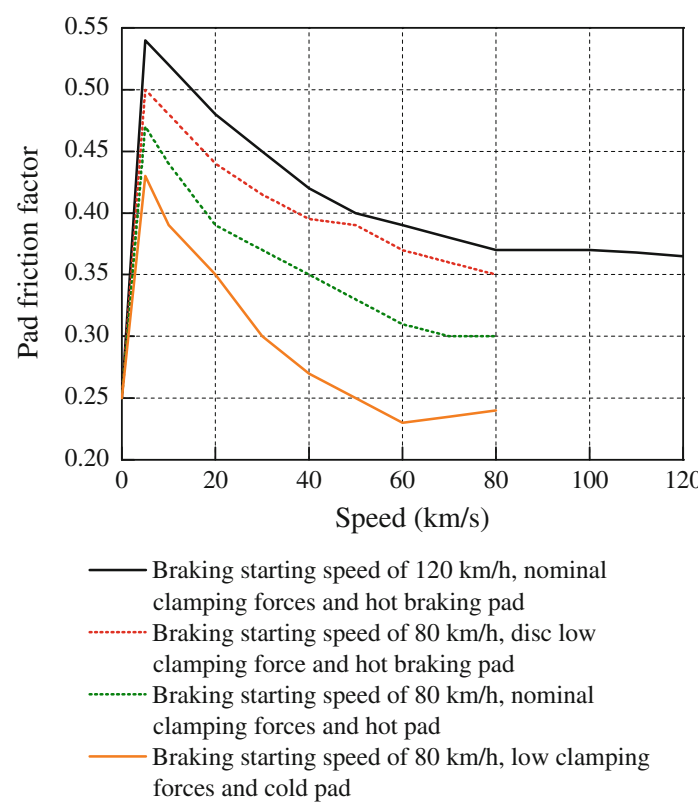

Fig. 12 Measured behavior of brake pad friction factor [12, 14], test performed on test rig [23] according UIC test program [22] by adopting the measured data of the friction [19] and using a narrower population of tests on the train (four braking tests over a population of 50), we identified a feasible behavior of the pad friction factor as a function of the traveling speed and the loading condition of the train (Fig. 13). In fact, the clamping forces of the brakes are self-regulated according to the vehicle weight and the traveling speed, once the mean values of the clamping forces with respect to the dissipated power is fixed.

By modifying the software TTBS01 according to the proposed brake pad behavior, we obtained the results satisfying the criteria for the software validation, with an acceptable value of $e_{\mathrm{s}}$ lower than $5.5 \%$ (exactly $5.35 \%$ ) as shown in Fig. 14. It is also worthy to point out that after the modification, the number of elements under the threshold of $2 \%-4 \%$ is more than doubled.

Finally, the first ten braking test simulations are compared with the experimental results in Figs. 15 and 16. One can see that a good-fitting agreement in terms of shape of speed profiles is evident. In particular, the results in Figs. 15 and 16 refer to emergency braking maneuvers

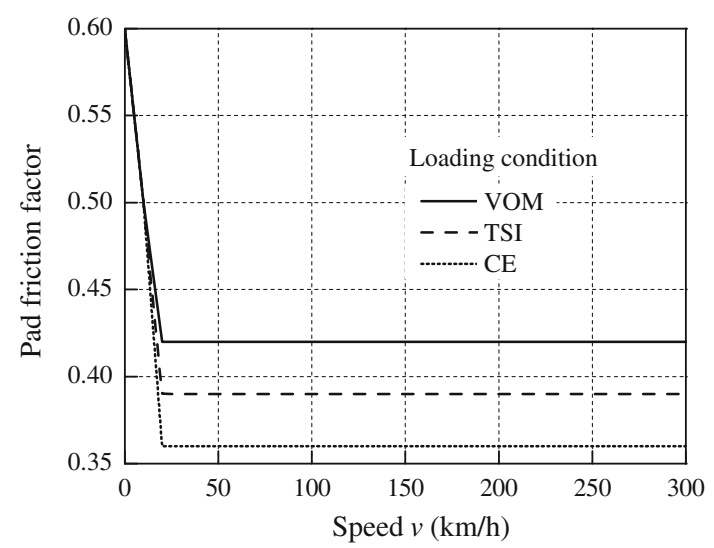

Fig. 13 Variable braking pad friction factor implemented on TTBS01 for the validation on EMU V250

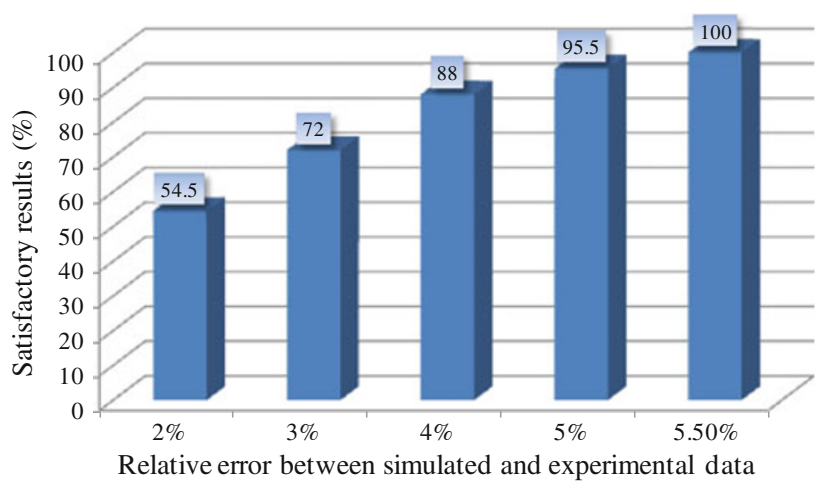

Fig. 14 Number of satisfactory simulation results as a function of the admissible value of $e_{\mathrm{s}}$ (variable pad friction factor is implemented) 


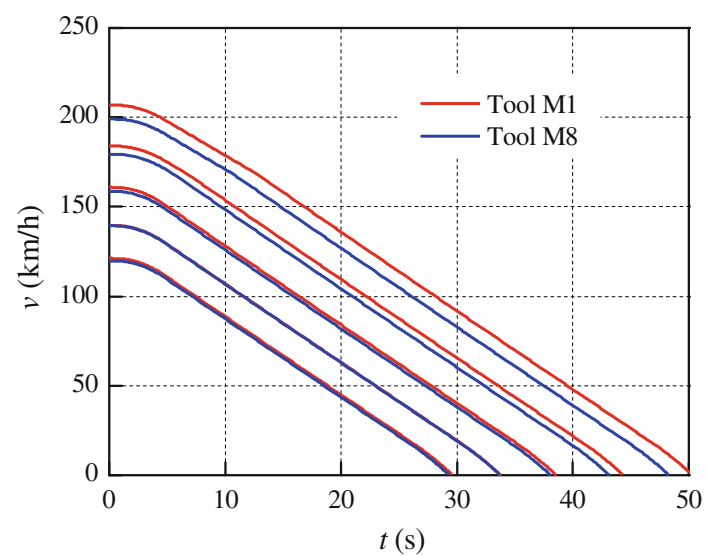

Fig. 15 Simulated test runs (different launching speed and motion sense) with emergency braking

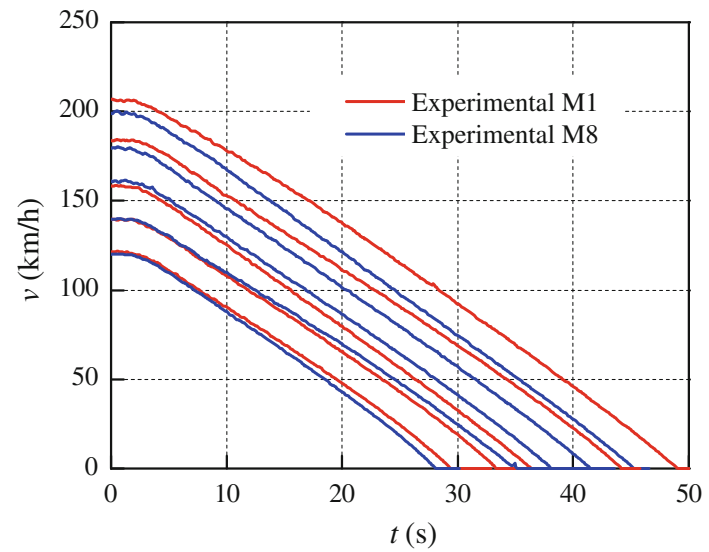

Fig. 16 Experimental speed profiles measured on ten braking test runs (different launching speed and motion sense) with emergency braking

performed in the VOM loading condition (vehicle tare), repeated twice in both the sense of motion over the line.

\section{Conclusion}

Preliminary validation of TTBS01 tool on EMU V250 experimental data has provided an encouraging feedback. As a consequence, TTBS01 should be considered both as a good tool for the preliminary simulation of braking systems and a base to build up real-time code for the monitoring of brake system performances. It is worthy to mention that the calculation method suggested by EN regulations in force [2] could be not reliable, since the typical behavior of braking forces, as influenced by braking pads, is not taken into account. For the purpose of UIC homologation [21], brake pads have to be widely tested, and even more complicated testing activities are performed by manufacturers. For each approved pad, a huge documentation concerning the variability of the friction factor with respect to speed and load conditions can be easily found. Therefore, the proposed method that calculates train braking performances by taking into account the variability of brake pad friction factors has a high feasibility. It is highly recommendable that the implementation of this feature in standard calculation methods is prescribed by regulations in force. Moreover, the use of reliability statistical methods proposed by ERRI documents should be further investigated.

Acknowledgments The authors wish to thank Ansaldo Breda for their competence and their practical and cooperative approach to problems, which greatly helped in realizing the positive conclusion of this research activity.

Open Access This article is distributed under the terms of the Creative Commons Attribution License which permits any use, distribution, and reproduction in any medium, provided the original author(s) and the source are credited.

\section{References}

1. Technical specification for interoperability relating to the rolling stock subsystem of the trans-European high-speed rail system referred to in Article 6(1) of Council Directive 96/48/EC, 30 May 2002

2. EN14531 Railway applications-methods for calculation of stopping and slowing distances and immobilisation edn, 15 Sept 2009

3. Piechowiak T (2009) Pneumatic train brake simulation method. Veh Syst Dyn 47(12):1473-1492

4. Vincze B, Geza T (2011) Development and analysis of train brake curve calculation methods with complex simulation. Adv Electr Electron Eng 5(1-2):174-177

5. Yasunobu S, Shoji M (1985) Automatic train operation system by predictive fuzzy control. In: Sugeno Michio (ed) Industrial applications of fuzzy control. North Holland, Amsterdam, pp 1-18

6. David B, Haley D, Nikandros G (2001) Calculating train braking distance. In: Proceedings of the Sixth Australian workshop on Safety critical systems and software vol 3, Australian Computer Society, Inc., Sydney

7. Cantone L, Karbstein R, Müller L, Negretti D, Tione R, Geißler HJ (2008) TrainDynamic simulation-a new approach. In: 8th World Congress on Railway Research, May 2008

8. Kang Chul-Goo (2007) Analysis of the braking system of the Korean high-speed train using real-time simulations. J Mech Sci Technol 21(7):1048-1057

9. Wilkinson DT (1985) Electric braking performance of multipleunit trains-Proceedings of the Institution of Mechanical Engineers, Part D. J Automob Eng 199(4):309-316

10. EN 15734-1 Railway applications-braking systems of high speed trains-part 1: requirements and definitions, Nov 2010

11. OBVT50 Brake performance test-vehicle type test procedureEMUV250, 14 May 2010

12. OBVT50 Brake performance test-vehicle type test procedureTest Report, 22 Nov 2010

13. UIC B 126/DT 414 UIC B 126/DT 414, Methodology for the safety margin calculation of the emergency brake intervention curve for trains operated by ETCS/ERTMS, June 2006

14. ERRI 2004 ERRI B 126/DT 407, Safety margins for continuous speed control systems on existing lines and migration strategies for ETCS/ERTMS, Nov 2004 (3rd draft) 
15. Malvezzi M, Presciani P, Allotta B, Toni P (2003) Probabilistic analysis of braking performance in railways. In: Proc. of the IMechE, J Rail Rapid Transit, vol 217 part F, pp 149-165

16. Malvezzi M, Papini R. Cheli S, Presciani P (2003) Analisi probabilistica delle prestazioni frenanti dei treni per la determinazione dei coefficienti di sicurezza da utilizzare nei modelli di frenatura dei sistemi ATC In: Atti del Congresso CIFI, Ricerca e Sviluppo nei Sistemi Ferroviari, Napoli, pp 8-9 Maggio 2003

17. Pugi L, Conti L (2009). Braking simulations of Ansaldo Breda EMU V250. In: Proceeding of IAVSD Congress 2009

18. Pugi L, Rindi A, Ercole A, Palazzolo A, Auciello J, Fioravanti D, Ignesti M (2011) Preliminary studies concerning the application of different braking arrangements on Italian freights trains. Veh Syst Dyn 8:1339-1365 ISSN: 0042-3114
19. Pugi L, Rindi A, Ercole A, Palazzolo A, Auciello J, Fioravanti D, Ignesti M (2009) Attività di studio e simulazione per l'introduzione del regime di locomotiva lunga. Ingegneria Ferroviaria 10:833-852 ISSN: 0020-0956

20. UIC 544-1 Freins-performance de freinage, 4th edn, Oct 2004

21. UIC 541-3 (2010) Brakes-Disc Brakes and their application, General Conditions for the approval of Brake Pads, 7th edn, July 2010

22. Approval tests with disc brake pads of the type Becorit BM 46 according UIC 541-3 VE (6th edn November 2006), Test Report 14 Dec 2007

23. Pugi L, Rinchi M (2002) A test rig for train brakes. In: AITC-3rd AIMETA International Tribology Conference, Salerno, p 18-20 Sept 2002 